\title{
THE GREAT WALL 3D DOCUMENTATION AND APPLICATION BASED ON MULTI- SOURCE DATA FUSION_ _ A CASE STUDY OF NO.15 ENEMY TOWER OF THE NEW GUANGWU GREAT WALL
}

\author{
Wei Hua ${ }^{1}$, Yunfei Qiao $^{2}$, Miaole Hou ${ }^{3,4,5, *}$ \\ ${ }^{1}$ China University of Mining \&Technology, Ding No.11 Xueyuan Road, Haidian District, Beijing - huawei199299@qq.com \\ ${ }^{2}$ Chinese Academy of Cultural Heritage, No.2 Gaoyuan Street Beisihuan Donglu, Chaoyang District, Beijing - 877883793@qq.com \\ ${ }^{3}$ School of Geomatics and Urban Spatial Informatics, Beijing University of Civil Engineering and Architecture, No.15Yongyuan \\ Road, Daxing District, Beijing - houmiaole@ bucea.edu.cn \\ ${ }^{4}$ Beijing Key Laboratory For Architectural Heritage Fine Reconstruction \& Health Monitoring, No.15Yongyuan Road, Daxing \\ District, Beijing - houmiaole@bucea.edu.cn \\ ${ }^{5}$ Engineering Research Center of Representative Building and Architectural Heritage Database, Ministry of Education, \\ No.15Yongyuan Road, Daxing District, Beijing - houmiaole@ bucea.edu.cn
}

Commission II, WG II/8

KEY WORDS: The Great Wall, Enemy Tower, 3D Documentation, Data Fusion, ICP Algorithm, Digital Conservation

\begin{abstract}
:
Laser scanning or photogrammetry are useful individual techniques for digital documentation of cultural heritage sites. However, these techniques are of limited usage if cultural heritage such as the Great Wall is in harsh geographical conditions. The Great Wall is usually built on the ridge with cliffs on both sides, so it is very difficult to construct scaffolding. Therefore, the three-dimensional (3D) data obtained from the traditional 3D laser scanning is not complete. As UAV cannot enter the enemy tower, the 3D structure data inside the enemy tower with unmanned aerial vehicle (UAV) photogrammetry is missing. In order to explore effective methods to completely collect the 3D data of cultural heritage under harsh geographical environment, this study focuses on establishing a 3D model and the associated digital documentation for the No.15 enemy tower of the New Guangwu Great Wall using a combination of terrestrial laser scanning and UAV photogrammetry. This paper proposes an integrated data collection method and reduces the layout of image control points using RTK-UAV technology, which improved work efficiency and reduced work risks as well. In this paper, the internal structure data of the Great Wall enemy tower was collected by laser scanning, the external structure data was collected by UAV photogrammetry, and data fusion was based on ICP algorithm. Finally, we obtained the complete and high quality 3D digital documentation of the Great Wall enemy tower, the data can be displayed digitally and help heritage experts complete the Great Wall's restoration. This study demonstrates the potential of integrating terrestrial laser scanning and UAV photogrammetry in 3D digital documentation of cultural heritage sites.
\end{abstract}

\section{INTRODUCTION}

The Great Wall is a military defense system in ancient China, involving walls as the main part and a large number of enemy towers, beacon towers, military castles. The Great Wall symbolizes national security and unity, and it has a special meaning for Chinese. It is not only a UNESCO World Heritage, but also a golden calling card for China's cultural heritage. With the increase of natural erosion and human activities, parts of the Great Wall's brick walls and enemy towers have been seriously damaged, so digital conservation is urgent.

Cultural heritage digital conservation combines modern surveying and mapping technology, computer technology, 3D documentation technology, and other new technologies to retain high-precision 3D digital data, providing scientific basis for the physical repair of the Great Wall. At present, the most widely used 3D acquisition technology is 3D laser scanning and UAV photogrammetry, both of which are independent technologies that can be applied to 3D documentation of cultural heritage. 3D laser scanning can quickly acquire the geometry of a large cultural heritage site, owing to its high operation speed, mobility, and accessibility (Heinz Rüther, 2009). UAV photogrammetry provides some alternative advantages when compared with laser scanning (Fernández-Lozan, 2016). UAV photogrammetry has a higher planar data acquisition rate in upper zones (e.g., the roof of a building) than terrestrial laser scanning (Young Hoon Jo, 2019).
Combining 3D laser scanning and UAV photogrammetry technology to establish 3D model of cultural heritage, some scholars have carried out relevant researches. In 2017, Guoli Wang performed a research on an ancient tower, which monitored the precise deformation using 3D laser scanning data and analyzed the disease of the tower using UAV photogrammetry technology (Guoli Wang, 2018). Bandung Institute of Technology established 3D model of the royal palace complex of Kasepuhan Cirebon, Indonesia using the multi-sensor data fusion method. The defect that a single sensor is only suitable for modelling under specific conditions was successfully solved (Arnadi Murtiyoso, 2018). Although the above researches have improved the quality of 3D data, the satuation that using of 3D laser scanning and UAV photogrammetry in harsh environments was not considered.

In this paper, the New Guangwu Great Wall No.15 enemy tower is located on the ridge, surrounded by cliffs. This situation makes it difficult to set up a scaffold to place a 3D laser scanner to scan the top half of the enemy tower, and the poor geographical environment makes it very dangerous to evenly arrange control points. It is difficult to obtain complete 3D data of the Great Wall enemy tower by independent 3D laser scanning or UAV photogrammetry. This paper aims at exploring the technology fusion method to acquire 3D data of cultural heritage in the harsh geographical environment. Therefore, we proposed a 3D data acquisition method combing terrestrial laser scanning with UAV photogrammetry, and divided the Great Wall enemy platform into two parts: internal structure and external structure. The UAV 
can't enter the enemy tower, so the 3D laser scanner was used to obtain high-precision point cloud data. The DJI Phantom 4 RTK UAV with built-in RTK technology was used to obtain highresolution image and generate $3 \mathrm{D}$ model and point cloud outside the enemy tower, where the 3D laser scanner is difficult to obtain high-quality data. As a new technology, the UAV with RTK can provide accurate image positioning for mountainous areas with weak GPS signal and areas where it is not easy to set up control points, improving work efficiency and ensures personnel safety. Finally, ICP algorithm was used to integrate the 3D data obtained independently by two different ways to generate complete 3D data of the Great Wall enemy tower.

The rest of the paper is organized as follows. Section 2 introduces the research area of this paper. Section 3 explains the methodology used in this study. Section 4 provides the results of the associated digital documentation of the No.15 enemy tower based on terrestrial laser scanning and UAV photogrammetry. Then, a discussion arises from the scientific significance and practical application of the research, and the limitations of this study are pointed out in Section 5. Finally, Section 6 provides the conclusion of the study and the prospect for future research.

\section{STUDY AREA}

The study area is located in New Guangwu village, Shanyin County, Shanxi Province, China (Figure 1). The NO.15 enemy tower of the New Guangwu Great Wall was built in the Hongwu Period of the Ming Dynasty (i.e., AD 1374), with a total length of about $3630 \mathrm{~m}$ and an elevation of about $1200-1700 \mathrm{~m}$. It is an UNESCO World Heritage. The New Guangwu Great Wall was built on the ridge with cliffs on both sides. Because it is easy to defend and hard to attack, the geographical environment of the Great Wall is bad, which also brings great challenges to the protection of the Great Wall. According to historical records, the latest maintenance of the New Guangwu Great Wall was in the Chongzhen period of the Ming Dynasty (i.e., AD 1640). After the Qing Dynasty, there was neither record of maintenance or protection of the Great Wall. Bearing a long time of natural disasters such as wind erosion and rain erosion, the existing parts have been seriously damaged.

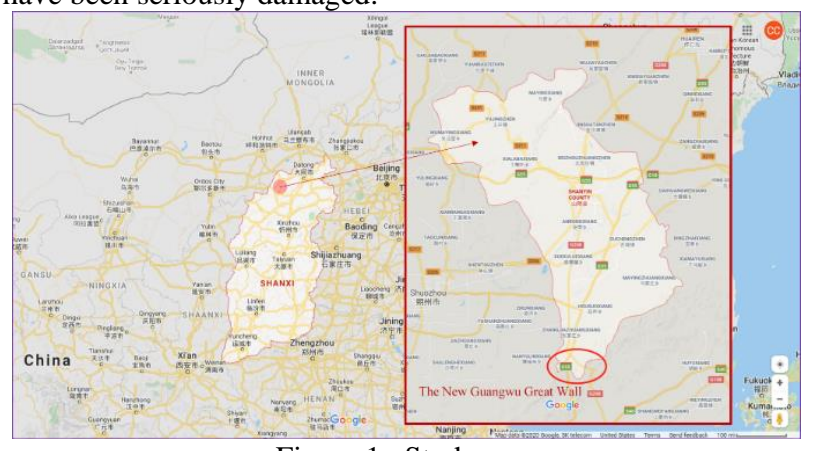

Figure 1. Study area

Enemy tower is a kind of hollow and windowed tower built across the wall. It is higher than the wall. The guards can live in it and store weapons and food to fight against the enemies. There are 19 enemy towers built on the New Guangwu Great Wall, four of which are still intact. The No. 15 enemy tower is the largest and the most complex of the remaining one on the Great Wall (Figure 2). The interior of the No.15 enemy tower is mainly composed of four arches in the East, West, South and North, and two passages in the middle of the building in the north-south and east-west directions. The cross arches in the middle passage divide the interior space of the enemy building into four uniform rectangular areas (Figure 3). The complex internal space structure of No. 15 enemy tower ensures the convenience of internal traffic, maximizes the utilization rate of internal space, facilitates the storage of troops and materials in wartime, and has high research and protection significance.

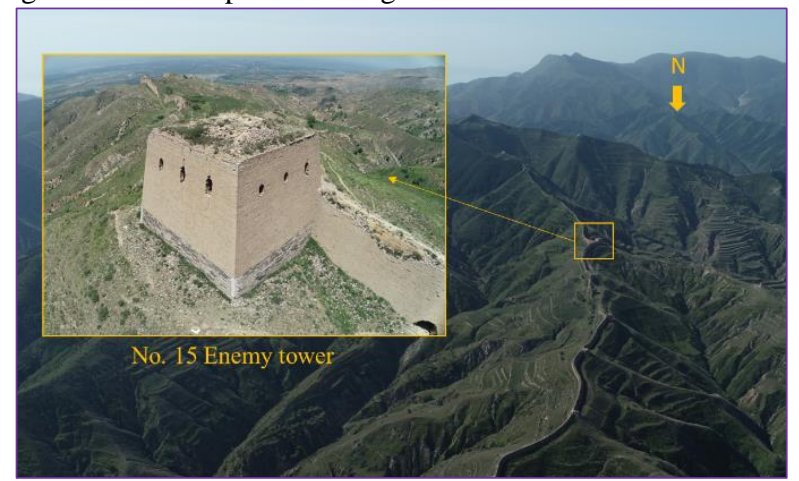

Figure 2. No. 15 Enemy tower

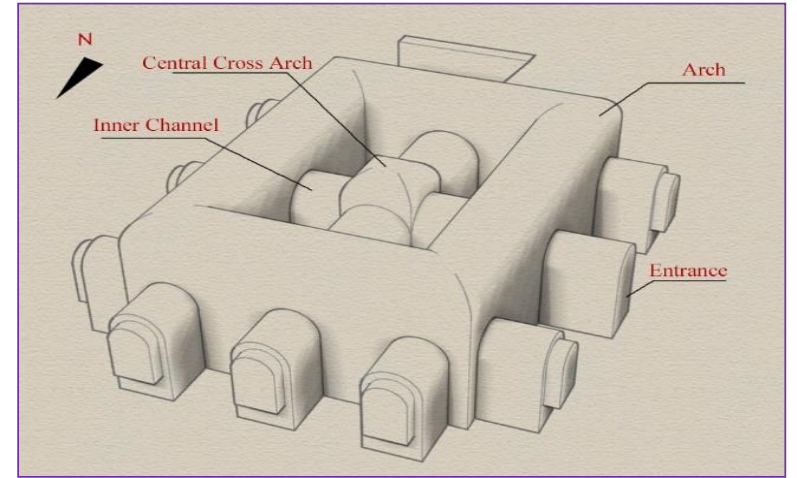

Figure 3. Internal structure of No. 15 Enemy tower

\section{METHODOLOGY AND IMPLEMENTATION}

In this study, the No. 15 enemy tower is located on the ridge. The GPS signal is weak and the two sides of the enemy tower are cliffs. As such, it is impossible to set up scaffolds to place laser scanners, and it is dangerous to arrange control points evenly according to the size of the study area. Considering the factors ranging from personnel safety to data acquisition cost and accuracy, this study decided to using a combination of terrestrial laser scanning and UAV photogrammetry method, and divided the data acquisition of the New Guangwu Great Wall No. 15 enemy tower into two parts: the internal structure and the external structure of the enemy tower.

Firstly, we used the Pentax S-3180v three-dimensional laser scanner to obtain the high-precision point cloud data of the inner structure of the enemy tower, and then used the DJI Phantom 4 RTK UAV to obtain the high-precision photos of the external part of the enemy tower. Finally, we used the ICP algorithm to register and integrate the data of the generated point cloud files, so as to compose the integrated 3D model of the new Guangwu Great Wall 15 enemy tower. As shown in Figure 4, the overall workflow consists of the acquisition of the point cloud data on the No. 15 enemy tower using terrestrial laser scanning and UAV photogrammetry and the $3 \mathrm{D}$ modeling process that combines the data from these two technologies. 


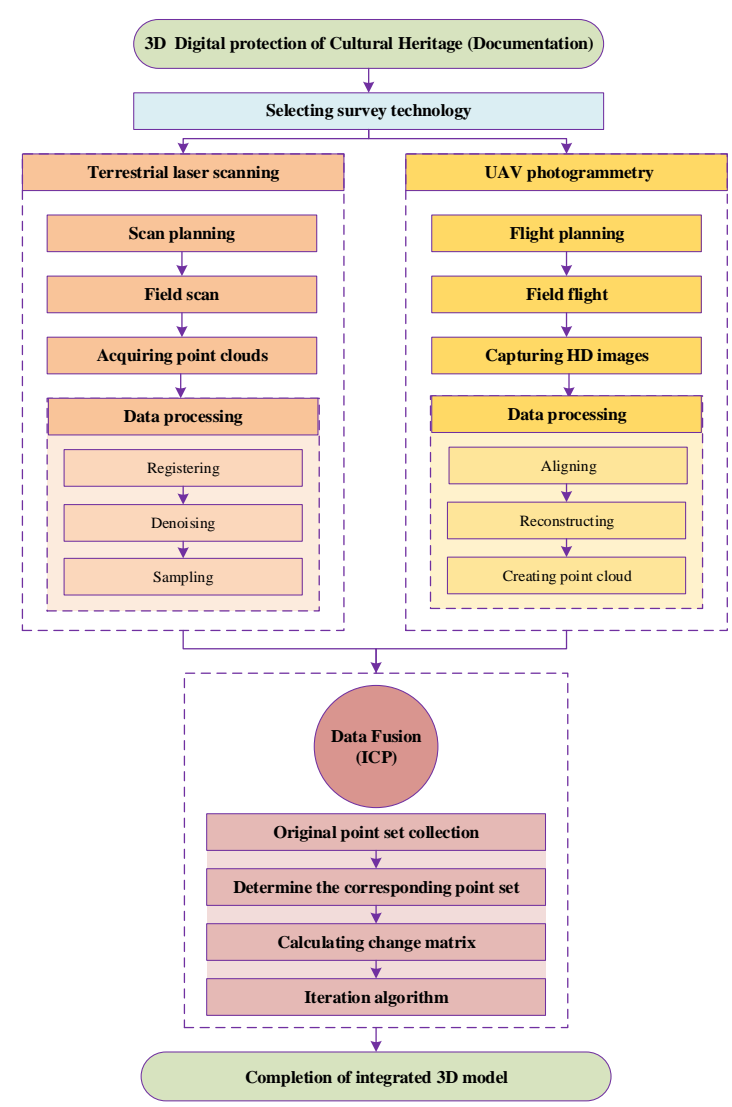

Figure 4. Workflow of integrated 3D modeling using terrestrial laser scanning and UAV photogrammetry

\subsection{Terrestrial Laser Scanning}

3D laser scanning has many advantages, such as high accuracy, non-contact and high efficiency. It has been widely used in digital documentation of cultural heritage in recent years (Feng Ming, 2020). The No. 15 enemy tower is a hollow tower with complex internal structure and dim light, so the UAV can't work in the enemy tower. The three-dimensional laser scanning is not affected by the environment light, which makes up for the defect of UAV. However, due to the fact that the enemy tower is built on the ridge, considering the safety of personnel and the cost of scanning, it is impossible to set up scaffolds to install 3D scanners, resulting in the poor quality of 3D scanning on the external upper side of the enemy tower.

In this study, the Pentax S-3180v three-dimensional laser scanner was used (Figure 5), which has a maximum measuring distance of $187 \mathrm{~m}$ and the resolution is $0.1 \mathrm{~mm}$, the scanning accuracy of $3 \mathrm{D}$ scanner is $0.3 \mathrm{~mm}$ within a distance of $10 \mathrm{~m}$. In addition, the scanner also has a 360-degree panoramic camera with a high dynamic range of HDR of 80 million pixels, which can generate color point clouds. In order to ensure the scanning quality, we set up a total of 23 stations, including 10 stations inside the enemy tower, 10 stations on the hillside outside the enemy tower (Figure 6 , red dots represent stations), and 3 stations on the top of the enemy tower (Figure 7, red dots represent stations). The scanning time of each station was about 15-20 minutes. The point cloud was processed by Geomagic studio 2013 software, and a complete color point cloud model was generated through postprocessing such as denoising and registration.

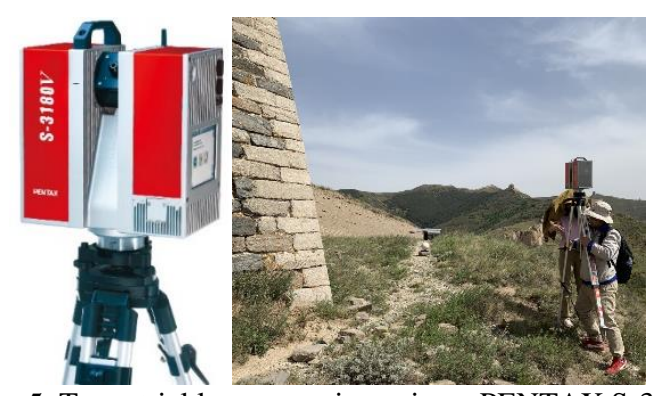

Figure 5. Terrestrial laser scanning using a PENTAX S-3180v 3D laser scanner

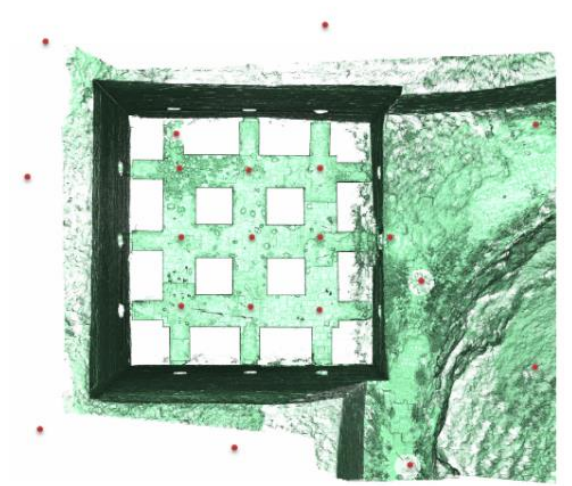

Figure 6. Scanning station inside and around the Enemy tower (Red dots represent stations)

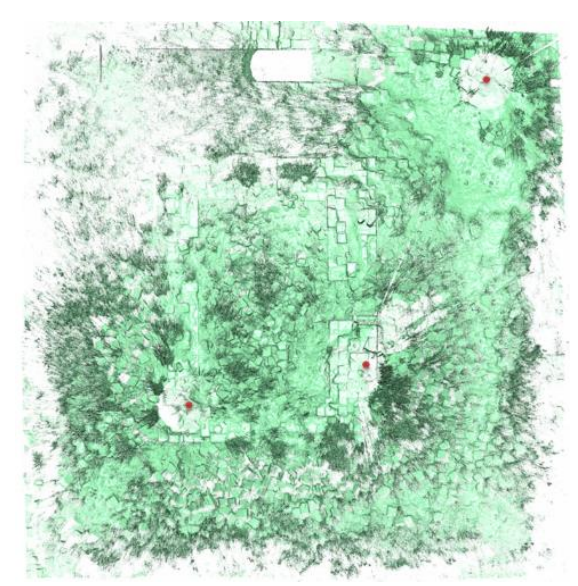

Figure 7. Scanning station on top of Enemy tower (Red dots represent stations)

\subsection{UAV Photogrammetry Generation}

Comparing with 3D laser scanning, UAV photogrammetry is more economical and efficient (Murtiyoso, 2018). In order to eliminate the influence of the poor quality of 3D scanning data outside the Great Wall, the UAV photogrammetry method was used in this paper. Since the cliffs are on both sides of the enemy's platform, assuming the control points are evenly arranged according to the size of the survey area, the operation would be very dangerous and inefficient. The latest DJI phantom 4 RTK was selected in this paper UAV (Figure 8), which combined RTK technology with traditional UAV photogrammetry, ensuring the accuracy of aerial survey. Meanwhile, only four control points (i.e., J15-1; J15-2; J15-4; J15-5) are set at the four corners of the top of No. 15 enemy platform and the wall beside the enemy platform, which can be safely reached by personnel. A check point (i.e., J15-3) (Figure 9) can reduce the workload and danger of control point measurement and greatly improve the work efficiency. 


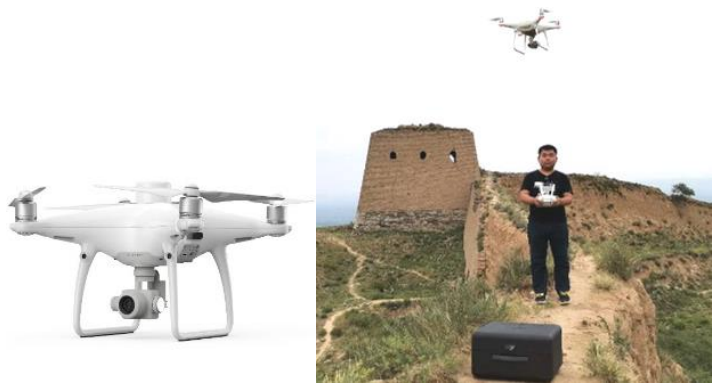

Figure 8. UAV photographing using a DJI Phantom 4 RTK

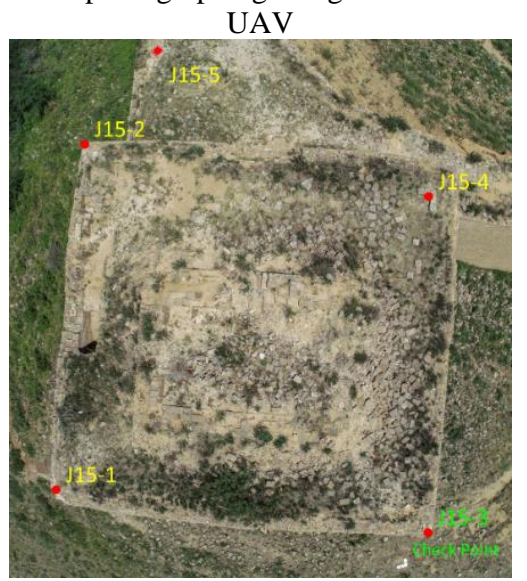

Figure 9. Image control point on top of Enemy tower DJI Phantom 4 RTK UAV is a high-precision rotor UAV with RTK technology. It is designed for low altitude photogrammetry applications, including centimeter-level navigation and positioning system and high-performance imaging system. It has horizontal positioning accuracy of $1 \mathrm{~cm}+1 \mathrm{ppm}$ RTK and vertical positioning accuracy of $1.5 \mathrm{~cm}+1 \mathrm{ppm}$ RTK. The DJI phantom 4 RTK UAV has a CMOS sensor with a 1-inch frame and 20 million pixels. The focal length of the lens is $8.8 \mathrm{~mm}$, the equivalent $35 \mathrm{~mm}$ focal length is about $24 \mathrm{~mm}$, the maximum image size is $5472 \times 3648$ pixels, and the ground sampling distance (GSD) in $100 \mathrm{~m}$ flight height can reach $2.74 \mathrm{~cm}$.

In this study, the angle of single lens was adjusted to 45 degrees, which was divided into 5 aerial surveys to simulate the 5 lens photogrammetry platforms, meeting the requirements of low cost and high precision. It showed promising results with regard to this experiment. In this paper, we set the percentage of course overlap and side overlap as $70 \%$, the relative altitude aa $50 \mathrm{~m}$, and the survey area as $156891 \mathrm{~m}^{2}$. Route and image acquisition location are shown in Figure 10.

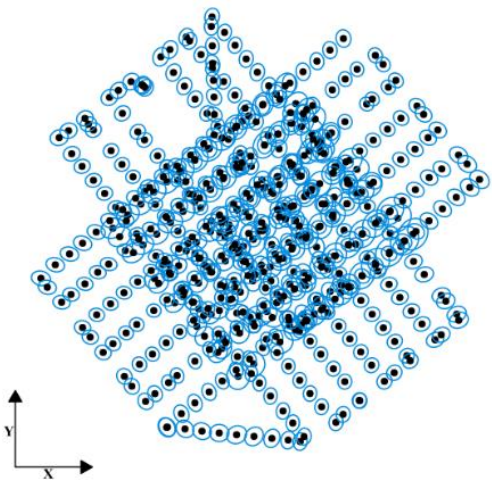

Figure 10. Air line and image location

In this paper, the UAV photogrammetry data processing used the Context Capture Center software. After conducting photo alignment, control points selection, aerial triangulation, dense point cloud generation, and grid model generation, the UAV photogrammetry data was used to generate dense point cloud and digital surface model (DSM).

\subsection{Iterative Closet Point (ICP) Registration}

The core algorithm of data fusion in this paper is ICP algorithm $(\mathrm{Xu}, 2016)$. The basic principle of ICP algorithm is: in the target point cloud $\mathrm{P}$ (i.e., external point cloud produced by UAV) and the source point cloud Q (i.e., internal point cloud obtained by 3D laser scanning) with matching, according to certain constraints, find the nearest point $\left(p_{i}, q_{i}\right)$, and then calculate the optimal matching parameters $\mathrm{R}$ and to minimize the error function. The error function $\mathrm{E}(\mathrm{R}, \mathrm{t})$ is:

$$
\mathrm{E}(\mathrm{R}, \mathrm{t})=\frac{1}{n} \sum_{i=1}^{n}\left\|q_{i}-\left(R p_{i}+t\right)\right\|^{2}(1)
$$

where $\quad n=$ number of nearest point pairs

$p_{i}=$ a point in the target point cloud $\mathrm{P}$

$\mathrm{q}_{i}=$ the nearest point corresponding to $p_{i}$ in the source point cloud Q

$\mathrm{R}=$ rotation matrix

$\mathrm{t}=$ translation vector

The above algorithm was made into a plug-in in the Meshlab software in this work, which was used for data fusion. Meshlab is an open source and extensible system software developed by the Department of computer science, University of Pisa, Italy, for processing and unstructured editing of point cloud data and triangular grid models.

\section{RESULTS}

In this study, a three-dimensional model and the associated digital documentation of the No.15 enemy tower of the New Guangwu Great Wall was established by using a combination of terrestrial laser scanning and UAV photogrammetry. Firstly, based on the Pentax S-3180v 3D laser scanner, the precise point cloud data of each scanning station in the No. 15 enemy tower was obtained. Using the Geomagic studio 2013 software, the point cloud denoising and registration of the station were completed, and finally the overall point cloud model of the No. 15 enemy tower was obtained (Figure 11).
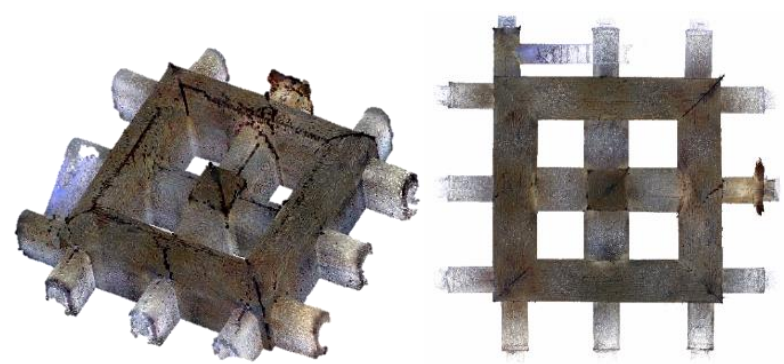

Figure 11. Internal structure of No. 15 Enemy tower (Point cloud)

Subsequently, based on the DJI phantom 4 RTK UAV photogrammetry, a total of 535 high-resolution images of the NO.15 enemy tower were obtained. The DSM model (Figure 12) and color point cloud model of the NO.15 enemy tower were generated by using the Context Capture Center software. The external dimension data of the enemy tower was obtained by using the measurement tools also provided by the same software above, providing accurate data for the entity repair of the NO.15 enemy tower (Figure 13). Finally, through the Meshlab software and ICP algorithm, the point cloud data obtained by these two methods were integrated to generate a complete $3 \mathrm{D}$ file 
containing the internal and external structure of the enemy tower (Figure 14).

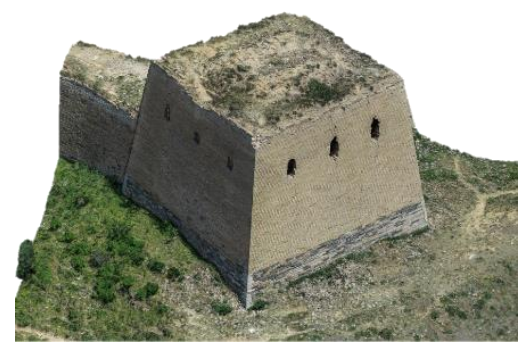

Figure 12. External structure of No. 15 Enemy tower (DSM model)
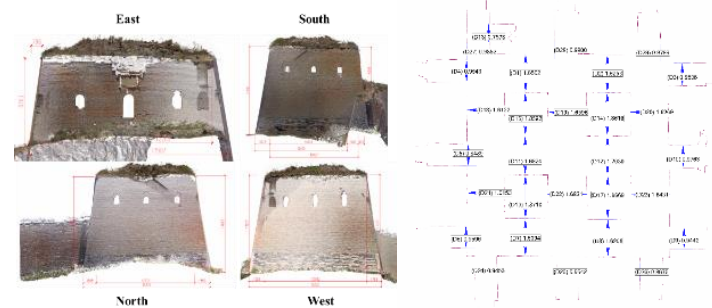

Figure 13. Size Information of No. 15 Enemy tower

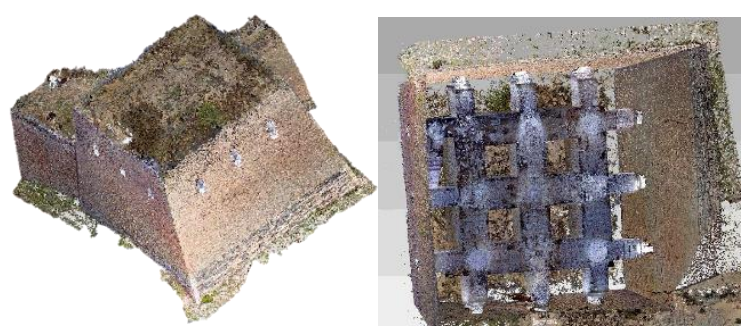

Figure 14. Result of integrated 3D modeling

\section{DISCUSSION}

The 3D laser scanning inside the enemy tower is consistent with the traditional 3D scanning method and standard of cultural heritage, and the accuracy is up to the standard (Uray, Firat, 2015). This paper focuses on the precision standard of UAV photogrammetry. Due to the limitation of geographical environment, UAV photogrammetry can't arrange control points and inspection points evenly according to the conventional requirements. Thus, only four control points and one inspection point were arranged on the top and around the enemy platform. In order to reduce the influence of this method on UAV photogrammetry accuracy, this study used DJI Phantom 4 RTK UAV with built-in RTK technology, and evaluated its accuracy by checking control point errors and reprojection errors per tie point.

In this study, 535 photos were collected, with ground sampling distance about 0.01580842 meters/pixel, which is higher than the 0.05 meters/pixel (GSD) required by 1:500 topographic map, ensuring the accuracy required for $3 \mathrm{D}$ archiving of cultural heritage. The reprojection errors per tie point is shown in Figure 15, which displays all tie points from top view (XY plane), side view (ZY plane) and front view (XZ plane), representing the reprojection error in pixels using different colors. The minimum reprojection error is 0.01 pixels and the maximum is 1.89 pixels. The average reprojection error is 0.47 pixels.

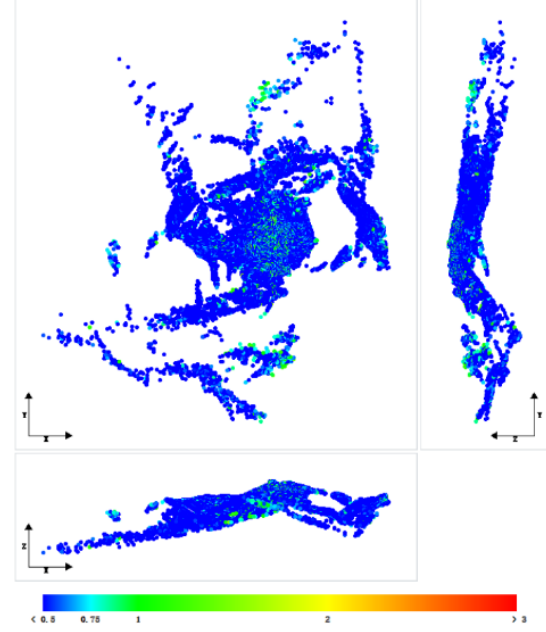

Figure 15. Reprojection errors per tie point

The tie point resolution is shown in Figure 16, which displays all tie points from top view (XY plane), side view (ZY plane) and front view (XZ plane), representing resolution in the individual point position with different colors. The values are in meters/pixel, with a minimum resolution of 0.00445 meters/pixel and a maximum of 0.24466 meters/pixel. The median resolution equals 0.01388 meters/pixel.

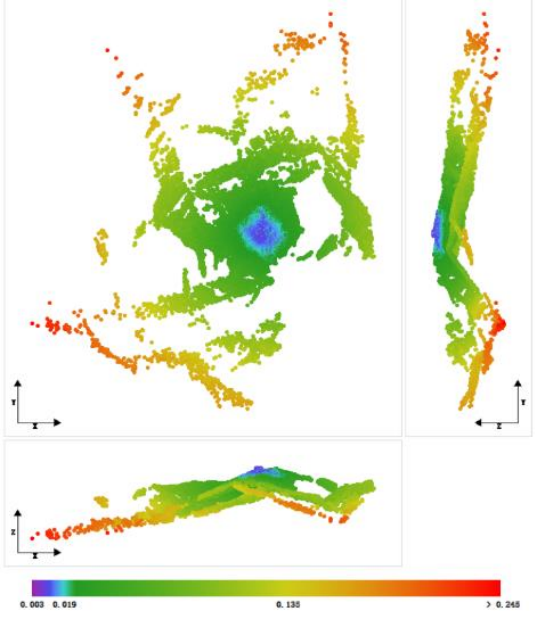

Figure 16. Tie point resolution

In this paper, the accuracy of UAV photogrammetry can also be verified to meet the requirements of cultural heritage $3 \mathrm{D}$ documentation by checking the control point and the reprojection error of the check point. As shown in Figure 17 and Figure 18, the reprojection error of the control point is 0.01 pixels, and the reprojection error distance is between $0.00003 \mathrm{~m}$ and $0.00009 \mathrm{~m}$; the reprojection error of the check point is 5.5 pixels, and the reprojection error distance is $0.02742 \mathrm{~m}$.

The above data shows that DJI phantom 4 RTK UAV can minimize the reprojection error, which indicate that it not only has a good modeling accuracy, but also can effectively reduce or eliminate the deployment of control points, ensuring the work efficiency and the safety of the measurement personnel. DJI phantom 4 RTK UAV can be used in the accurate measurement of cultural heritage in harsh environment. 


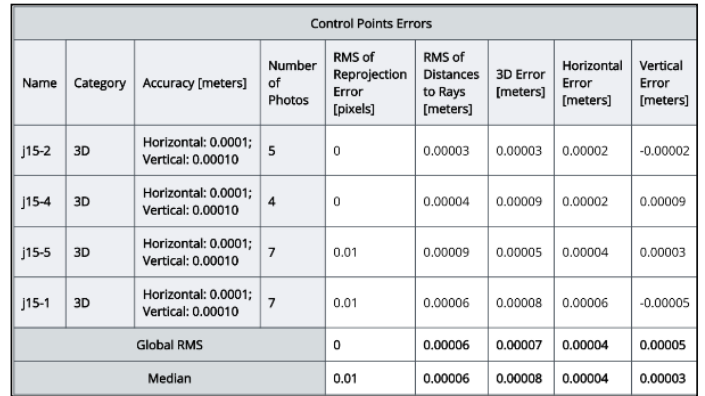

Figure 17. Control points errors

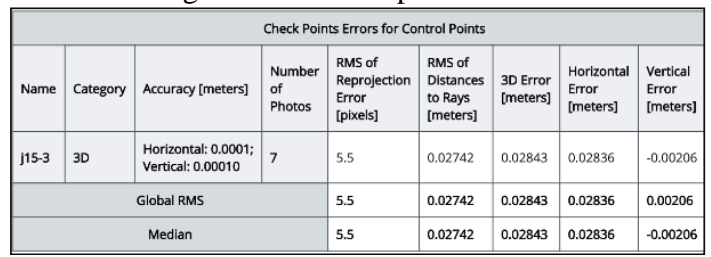

Figure 18. Check points errors for control points

\section{CONCLUSIONS}

This study focuses on using a combination of terrestrial laser scanning and UAV photogrammetry to establish a 3D model and the associated digital documentation of the No.15 enemy tower of the New Guangwu Great Wall. Based on these two techniques, the information of the external and internal structures of the enemy tower was obtained. The accuracy of the DJI Phantom 4 RTK UAV was analyzed: The check point's horizontal and vertical errors were given according to each control point respective spatial reference system, and the accuracy conforms to the requirements of cultural heritage digital documentation. The study proves that in the harsh environment, the RTK-UAV can be used to reduce the image control points and improve the work efficiency. Consequently, photogrammetry could increase the value of a 3D model by complementing the point cloud data for the upper parts of buildings that are difficult to acquire through laser scanning.

In this paper, we used multi-sensor to obtain 3D data, and got a complete 3D model, which provided a new method for cultural heritage 3D digital documentation in harsh environment. This method can be extended to many kinds of immovable cultural heritage 3D digital documentation. However, due to the harsh environment, more control points were not set in this study, and the accuracy of 3D data produced by UAV photogrammetry could not be further checked through checkpoints, which is a limitation of this paper. Moreover, cross-validation with various other measurement techniques such as total station can be taken into account to increase the reliability of positional accuracy. In the future, we will combine more measurement techniques and add more control points to potentially optimize the digital documentation of the cultural heritage. The 3D integrated model of terrestrial laser scanning and UAV photogrammetry seems to be a powerful tool for the digital documentation of the cultural heritage which is in harsh environment.

\section{ACKNOWLEDGEMENTS}

Acknowledgements of support for the Great Wall scholar training program of Beijing Municipal University high level teacher team construction support program (NO. CIT\&TCD20180322).

\section{REFERENCES}

Azmi, Mohamad Aizat Asyraff Mohamad, et al. 2018. 3D Data Fusion Using Unmanned Aerial Vehicle (UAV) Photogrammetry and Terrestrial Laser Scanner (TLS). Proceedings of the Second International Conference on the Future of ASEAN (ICoFA) 2017-Volume 2. Springer, Singapore.

Feng Ming, Yang Minglong, Xia Yonghua, Bai Hongqiang. 2020. 3D modeling of high cliffs by 3D laser scanning and tilt photogrammetry. Science of Surveying and Mapping, 45 (01): $99-107+122$

Fernández-Lozano, J., \& Gutiérrez-Alonso, G. 2016. Improving archaeological prospection using localized UAVs assisted photogrammetry: An example from the Roman Gold District of the Eria River Valley (NW Spain). Journal of Archaeological Science: Reports, 5, 509-520.

Fryskowska, A., et al. 2015. ALS and TLS data fusion in cultural heritage documentation and modeling. The International Archives of Photogrammetry, Remote Sensing and Spatial Information Sciences 40.5: 147.

Grenzdörffer, G. J., F. Niemeyer, and A. Frank. 2015. Symbiosis of UAS photogrammetry and TLS for surveying and 3D modeling of cultural heritage monuments-a case study about the cathedral of St. Nicholas in the city of Greifswald." The International Archives of Photogrammetry, Remote Sensing and Spatial Information Sciences 40.1: 91.

Guoli Wang, Guikai Wu, Yanmin Wang, Ming Guo, Jianghong Zhao, Chao Gao. 2018. Deformation monitoring of ancient pagodas with multi-source data. Journal of Geo-Information Science, 20 (04): 496-504

Heinz Rüther, Chazan, M., Schroeder, R. , Neeser, R. , Held, C. , \& Walker, S. J. , et al. 2009. Laser scanning for conservation and research of african cultural heritage sites: the case study of wonderwerk cave, south africa. Journal of Archaeological Science, 36(9), 0-1856.

Jo, Y. H., \& Hong, S. 2019. Three-dimensional digital documentation of cultural heritage site based on the convergence of terrestrial laser scanning and unmanned aerial vehicle photogrammetry. ISPRS International Journal of GeoInformation, 8(2), 53.

Martorelli, Massimo, Claudio Pensa, and Domenico Speranza. 2014. Digital photogrammetry for documentation of maritime heritage." Journal of Maritime Archaeology 9.1: 81-93.

Murtiyoso, Arnadi, et al. 2018. Multi-scale and multi-sensor 3D documentation of heritage complexes in urban areas. ISPRS International Journal of Geo-Information 7.12: 483.

Uray, Firat, A. Metin, and A. Varlik. 2015. 3D Architectural Surveying of Diyarbakir Wall's Ulu Beden Tower with Terrestrial Laser Scanner. Procedia Earth and Planetary Science 15: 73-78.

Xu, Z. Wu, T. H. Shen, Y., \& Wu, L. 2016. Three dimentional reconstruction of large cultural heritage objects based on uav video and tls data. ISPRS - International Archives of the Photogrammetry, Remote Sensing and Spatial Information Sciences. 